\title{
Critical Thinking as Predictor of Drawing Ability
}

\author{
Edward O. Stewart
}

\section{Introduction}

Much attention of late, has been given to the relationship between the quality of education and involvement in the arts. Hanna (1992), Horn and Sieder (1992), Fowler (1994, Gardiner, Knowles and Heffrey (1996), and Bezruczko (1997) have documented academic success in the presence of a strong arts program, although the specific relationship in terms of cause and effect has not as yet been determined. There may be many possible reasons for this relationship. The effect may be motivational so that good arts programs encourage students' desire to learn (Sukraw-Ebert, 1988). Quality arts programs may also train the mind to patterns of thinking which aid in the learning of other subjects, as seems to be suggested in studies such as Gardiner, Knowles, and Heffrey (1996) and Bežruczko(1997). It could be that the types of activities in which students are engaged during arts classes constitute the type of rich, stimulating environments which according to Diamond and Hopson "unmistakably influence the brain's growth and learning" (1998, pp. 107-108). There is also the possibility that intelligence, critical thinking, and the discipline of thinking in the arts are interdependent, with each benefiting from the other and each depending on the other.

The interest in critical thinking over the last decade may be an opportunity for understanding the connection between the arts and academics as critical thinking is common to all. The literature on critical thinking indicates that critical thinking abilities in one area are not transferable and do not indicate critical thinking ability in another area. However, these ideas are untested in the area of art making skills and general critical thinking. There is some empirical evidence of a correlation between achievement scores in science and general critical thinking in research conducted by Troxel and Snider (1970) and Bitner (1991). If critical thinking is a pattern of thinking, then someone who is a good, general critical thinker should be able to learn in other areas and begin to think critically in those areas once the subject specific information (rules of the game) have been introduced. Kurfiss (1988) argues that critical thinking is subject specific because "studies in artificial intelligence. . have made clear that a considerable task-specific knowledge is required to solve even 'simple' problems" (p. 11). However, what if critical thinking is like a computer program (to carry on the artificial intelligence analogy) and the subject related material were the data? The program must sit dormant until the correct amount and type of data are fed into the computer for that particular program to work. Observation about results concerning transfer may be more about knowledge acquisition than thinking frames which are present (the program in the a computer), but can't be used until enough subject specific information is acquired. It may also be that, rather than subject specificity, the application of critical thinking strategies are linked to task familiarity.

This study is focused on discovering whether a relationship exists between drawing ability and general critical thinking. The study does not examine 
cause and effect, as those results cannot be obtained from a correlation or regression analysis. Rather, the focus of the study is whether a relationship exists between the two main variables. The extraneous variables are controlled by including them as independent variables. A stepwise regression equation is used to statistically analyze the data. Because there are many factors effecting both variables, a regression analysis rather than a straight correlation is though to be the more effective procedure.

\section{Participants}

The participants for the study included students from secondary introductory and advanced level art classes from grades 9-12. The participants came from three schools in suburban areas in a Midwestern state. There were a total of 137 participants in this study. Ninety-two students were from introductory art classes and 45 students were from advanced art classes. There were 64 males and 73 females which in terms of percentage of the whole is $47 \%$ males and $53 \%$ females. Students in the study were in grades 9-12; 19 students were from 9thgrade, 47 were 10th-graders, 29 were 11 th-graders, and 42 were 12 th-graders. In terms of percentage of the whole, the break down is $14 \%$ 9th-graders, $34 \%$ 10th-graders, $21 \% 11$ th-graders, and 31\% 12th-graders.

\section{Research Design}

Three teachers from three different schools participated in the study. Each teacher taught at least one section of advanced art classes and at least one section of introductory art classes. One school contributed participants from three sections of both introductory and advanced classes. The 137 participants came from a total of ten sections. Subjects were asked to participate in the study. Those students who chose to participate in the study were asked to sign a letter indicating their agreement to participate. Because participation was voluntary, some students in each section chose not to participate, so that the final 137 participants represent varying percentages of the total number of students in each section. Students in those sections who turned in all completed materials related to the study were counted as participants in the study. Human subject data were coordinated by the cooperating teachers so that the same participant had the same number on each instrument, but the researcher had no way of identifying individual participants.

\section{Instrumentation and Data Collection Procedures}

Students were given the three instruments for the study with the same student ID number on each of these documents, so that the documents could later be correlated. Participants were asked to fill out a survey to identify independent variables (age, gender, grade, family member in the arts, years of formal training in art, the experience of private art lessons, and participation in advanced or honors Art, English, Science, and/or Math classes). They were then, on separate occasions, administered the two test instruments used in this study: The Cornell Critical Thinking Test - Z (CCTT-Z) (Ennis, R., Millman, J., \& Tomko, T. 1985), and the Clark Drawing Abilities Test (CDAT) (Clark, 1989). 
Both tests were timed. Teachers were allowed great latitude in deciding when they would administer the tests to the participants in each section of their classes to be less intrusive in the curriculum of cooperating teachers. Some teachers administered the CDAT first and others administered the CCTT first. Some teachers administered both tests within one week and others administered the tests several weeks apart. Since the CDAT contained four drawing assignments at 15 minutes each and the classes were all 50 minutes, the drawing tests were administered over a two day period. The CCTT was a 50 minute test administered in one class periods.

\section{The Schools}

School A is a suburban high school with a total 9-12 population of about 1,500 students. The introductory art classes average about 32 students, and the advanced classes average about 15 students per class. One advanced and one introductory class were used for this study. The community in which School A was located contained a minority population which made up about $12 \%$ of the total population.

School B is a small suburban high school with a total 9-12 population of about 900 students. The introductory art classes average about 26 students and the advanced classes average about six students per class. The community in which School B was located contained a minority population which made up about $12 \%$ of the total population. One advanced and one introductory class were used for this study.

School C, like school B, is a small suburban high school with a total 9-12 population of about 960 students. The Art II classes average about 25 students and the Advanced classes (Art III/IV) average about 15 students per class. Three Art II classes were used in this study and three Art III/IV classes were used. The community in which School $\mathrm{C}$ was located contained a minority population which made up $12.6 \%$ of the total population.

\section{Results}

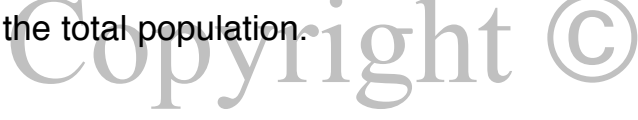

Results indicate that a statistically significant relationship exists between the dependent variable (the Clark Drawing Abilities Test) and the Cornell Critical thinking Test $(C C T T)(p<.05)$. Three independent variables were found to function as predictors for the dependent variable (CDAT) when a stepwise regression analysis was applied (see Table 2). These independent variables were participation in advanced or honors Art classes (HRT), experience of private lessons (PVTRT), and scores on the Cornell Critical Thinking Test (CCTT). 
Table 1

Analysis of Variance

\begin{tabular}{|c|c|c|c|c|c|}
\hline Source & DF & $\begin{array}{l}\text { Sum of } \\
\text { Squares }\end{array}$ & $\begin{array}{l}\text { Mean } \\
\text { Square }\end{array}$ & F Value & Prob $>F$ \\
\hline Model & 12 & 15.43 & 1.28 & \multirow[t]{3}{*}{2.70} & \multirow[t]{3}{*}{0.002} \\
\hline Error & 124 & \multirow[t]{2}{*}{58.96} & \multirow[t]{2}{*}{0.47} & & \\
\hline C Total & 136 & & & & \\
\hline Roc & & & \multirow{3}{*}{$\begin{array}{l}\text { R-squar } \\
\text { ADJ R-S }\end{array}$} & & \\
\hline Dep Mea & & & & 0.13 & \\
\hline C.V. & & & & & \\
\hline
\end{tabular}

Table 2

Summary of Stepwise Procedure for Dependent Variable CDAT

\begin{tabular}{|c|c|c|c|c|c|c|c|}
\hline $\begin{array}{l}\text { Variable } \\
\text { Step }\end{array}$ & $\begin{array}{l}\text { Numb } \\
\text { Enter }\end{array}$ & d Removed & $\begin{array}{l}\text { Partial } \\
\mathrm{R}^{\star \star 2} 2\end{array}$ & $\begin{array}{l}\text { Model } \\
\mathrm{R}^{\star \star} 2\end{array}$ & $C(p)$ & $\mathrm{F}$ & Prob $>F$ \\
\hline $1 \mathrm{HRT}$ & 11 & $1<0$ & 0.109 & 0.109 & 6.340 & 16.589 & 0.0001 \\
\hline 2 PVTRT & & 2 & 0.041 & 0.151 & 1.906 & 6.4865 & 0.00 \\
\hline 3 CCTT & & 3 & 0.029 & 0.180 & -0.699 & 4.774 & 0.03 \\
\hline
\end{tabular}

Note. Variable HRT indicates students enrolled in advanced or honors Art classes.

Variable PVTRT indicates the participation or experience of private art classes.

Variable CCTT is the Cornell Critical Thinking Test. 


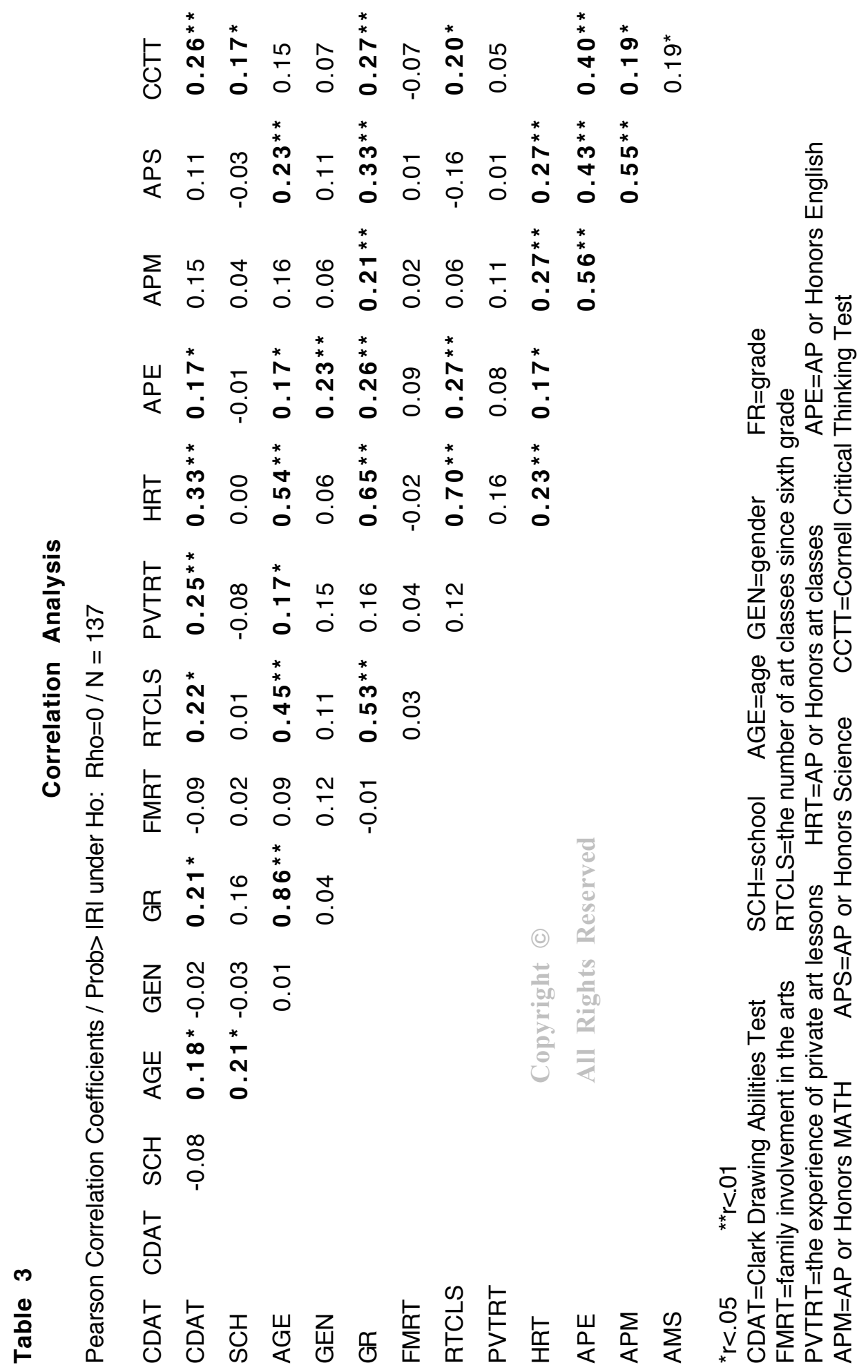

178

Marilyn Zurmuehlen's Working Papers In Art Education 1998-1999 
Many of the independent variables were found to intercorrelate (see Table 3). The most interesting of the intercorrelations was the AP or honors classes, which all significantly intercorrelated with each other. This fits into the observations made by Yochim (1967) and Clark and Zimmerman (1984) that the artistically talented student is not the academic malcontent and social outcast, but rather is quite socially and academically capable. Indeed, all of the advanced classes intercorrelate, suggesting that students who take one AP (Advanced Placement, advanced, or honors) class are likely to take all or many available AP or advanced classes. This fits in well with the Hurwitz (1983) notion of a "clustering of aptitudes" (p. 17) with talent in art being the "tip of the iceberg" (p. 17). This is to say that artistic talent is a complex cluster of aptitudes or mental abilities of which artistic ability is one manifestation. Artistic talent is probably dependent on many abilities especially in the light of the fact that all of the independent variables in this study account for only $13 \%$ of the variability of the scores on the dependent variable. It also fits with Clark's hypothesis that intelligence and drawing ability are related.

Another significant intercorrelation noted in the correlation analysis in Table 3 which is consistent with the literature on critical thinking was APE (Advanced or honors English) with the Cornell Critical Thinking Test (CCTT) $(r=.40)$. This is expected since the items on the test are language based. The review of literature highlights a relationship between critical thinking and language ability (Thompson \& Melancon, 1987) and that reading level correlates to scores on tests for critical thinking (Raburn \& Van Schuyver, 1984). Language development correlates to development of problem solving strategies. Ellis and Siegler (1994) also found that students learned better and were more capable of transferring learning to new situations when they verbalized about their observations rather than having someone tell them the information. Drawing also involves participants in that type of self-discovery.

Ennis, Millman, and Tomko (1985), Frisby (1991), Adiseshiah (1977), Miller (1990), and Phillips, Uprichard, and Johnson (1974) all indicate a relationship between age and critical thinking ability although Frisby's meta-analysis showed some contradictory information. This study did not find such a relationship although the age range was so small (14-19 with a mean age of 16.4) that it might be considered, for the CCTT (Cornell Critical Thinking Test) variable, to be homogeneous. It may, however, be interesting to note that in the correlation analysis there is significant intercorrelation between GR (grade level) and the CCTT ( $p>$.07) which indicates that critical thinking ability is more a function of learning than simply getting older.

Meier (1939) discussed the importance of encouragement, nurturing, and modeling in the development of artistically talented individuals. Artistically talented people are influenced by a number of factors which are inherited, acquired, and learned. The presence of a close friend or mentor to encourage the developing talent is necessary. The findings in this study were not consistent with this observation showing no statistically significant intercorrelation with this variable. There was, however, a very small number of students $(n=11)$ reporting artistic involvement of family members which may have been the reason for this 
lack of significant correlation in this study. The questionnaire may also have been worded to be more specific about a mentoring relationship.

According to the literature, art talent does not seem to be bound by age or gender. Clark (1989b) observed that there was no correlation between age and the CDAT. The correlation analysis shows an intercorrelation between age and the CDAT, but age also intercorrelates with RTCLS (number of art classes taken since 6th grade) and HRT (AP or honors Art class). Younger students have taken fewer art classes and are less likely to be enrolled in advanced or honors Art classes because of the prerequisites requiring that introductory art classes be taken. The significance of age is probably thus mitigated by the fact that mainly older students have advanced training in art. There was no statistically significant intercorrelation between any of the other variables and gender.

\section{Discussion}

This study, being a correlation study, does not address cause and effect. What part general critical thinking has on drawing ability, or to what extent drawing ability effects the development of drawing ability, is not known. What is known from this study is that there is a relationship between general critical thinking and drawing ability, and general critical thinking is a statistically significant predictor of drawing ability. It must also be stressed that general critical thinking along with all of the independent variables contributed only $13 \%$ of the variance in the drawing scores. It is certain that there are other factors beyond the scope of this study that contribute to artistic talent, of which general critical thinking is but one. Other factors may be socioeconomic status, IQ tests of spatial understanding, and scores on math, science and reading measures (as opposed to reports of taking advanced classes in those subjects).

Future studies should be conducted to expand and clarify the information gained through this research. Since few students scored at or above the 50th percentile on the CCTT-Z, a similar study might be conducted using the CCTT-X $t$ $o$ ascertain whether the degree of difficulty may have affected the scores on that independent variable in relation to the dependent variable. The CCTT-Z is a test designed for college students, adults, and academically gifted high school students, whereas the CCTT-X is designed for fourth to 12th grade students. The CCFT- $Z$ was used because gifted high school students were a focus of this study, but there were many average students that were participants in this study.

Another study is suggested that would focus on the degree to which drawing ability influences general critical thinking. This study would use the measure of critical thinking as the dependent variable and the test for drawing ability would be used as one of many independent variables. It is also suggested that fewer dichotomous variables be used. Continuous variables will net more meaningful data.

Finally, there need to be more studies to account for more of the variability on the CDAT as the independent variables account for only $13 \%$ of the variability in the scores on that dependent variable. Diamond and Hobson (1998) have 
found that minds are better developed in richer environments suggesting the effect that socioeconomic status might play on brain growth and development. Researchers Clark and Zimmerman (1984) and Yochim (1967) have indicated a relationship between IQ and artistic talent. Therefore, it is suggested that socioeconomic status and IQ might be included in a future study as independent variables.

\section{References}

Adiseshiah, W. T. (1977). Psychology of critical thinking. Journal of Psychological Research, 21, 227-232.

Bezruczko, N. (1997). Links between children's clay models and school achievement. (Eric Document Reproduction Service, report No. ED410 031).

Bitner, B. L. (1991). Formal operational reasoning modes: predictors of critical thinking abilities and grades assigned by teachers in science and mathematics for students in grades nine through twelve. Journal of Research in Science Teaching, 28, 265-274

Clark, G. A. (1989). Clark's drawing abilities test. Bloomington, IN: A.R.T.S. Publishing Co., Inc.

Clark, G.\& Zimmerman, E. (1984). Educating artistically talented students. Syracuse, NY: Syracuse University Press

Diamond, M. \& Hopson, J. (1998). Magic Trees of the Mind. New York: Dutton.

Ellis, S. \& Siegler, R. (1994). Development of problem solving. In R. J. Sternberg (Ed.) Thinking and Problem Solving: Handbook of Perception and Cognition. NY: Academic Press, 333-367

Ennis, R., Millman, J., \& Tomko, T. (1985). Cornell test for critical thinking. Pacific Grove CA: Critical Thinking Press and Software.

Fowler, 1 C. (November, 1994). Strong arts, strong schools. Educational leadership, 52 (3), 4-9.

Frisby, C. L. (1991). A Meta-analytic investigation of the relationship between grade level and mean scores on the Cornell Critical Thinking Test (level X). Measurement and evaluation in counseling and development, 23, $162-170$.

Gardiner, M., Knowles, F., \& Heffrey, D. (1996, May 23). Learning improved by arts training. Nature, 381, 284.

Hanna, L. (April 1992). Connections: Arts, academics, and productive citizens. Phi Delta Kappa, 73, (8), 601-607. 
Horn, M. \& Sieder, J. (1992, March 30). Looking for a Renaissance: The campaign to revive education in the arts, U.S. New and World Report, 52-54.

Hurwitz, A. (1983). The gifted and talented in art: A guide to program planning. Worchester, MA: Davis Publications, Inc.

Kurfiss, J. G. (1988) Critical thinking: Theory, research, practice, and possibilities. ASHE-ERIC Higher Education Report no. 2. Washington, DC: Association for the Study of Higher Education.

Meier, N. C. (1939). Factors in artistic aptitude: Final summary of a ten year study of special ability. Psychological Monographs, 51, 140-158. Princeton, NJ: The Psychological Review Co.

Phillips, E. R., Uprichard, A. E., \& Johnson, H. L. (1974). The correlation of selected mathematical measures with problem solving ability. Florida Journal of Educational Research, 16, 3-11.

Sukraw-Ebert, J. M. (1988). Arts not apart, but a part. Principal, 67 (3), 11-14.

Thompson, B. \& Melancon, J. G. (1987) Validity of a measure of critical thinking skills. Psychological Reports, 60 (3pt. 2), 1223-1230.

Troxel, V. A., \& Snider, C. F. (1970). Correlations among student outcomes on the test on understanding science, Watson-Glaser critical thinking appraisal, and the American chemical society cooperative examinationgeneral chemistry. School Science and mathematics, 70 (1), 73-76.

Yochim, L. D. (1967). Perceptual growth in creativity. Scranton, PA: International Textbook Co.

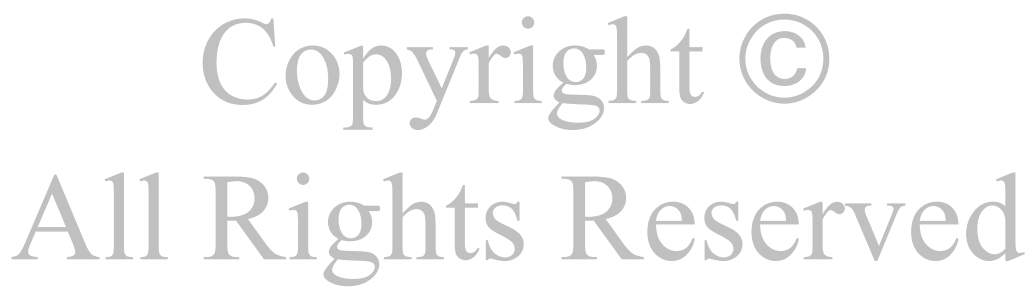

